\title{
RENTABILIDADE DAS DISTRIBUIDORAS DE COMBUSTÍVEIS EM RELAÇÃO À IMPORTAÇÃO DA GASOLINA A E DO ÓLEO DIESEL
}

\author{
Alexandre Godinho Bertoncello, Debora Aline Lima Oliveira \\ Universidade do Oeste Paulista - UNOESTE, Curso de Administração, Presidente Prudente, SP. E_mail: \\ debora.contato@hotmail.com.br
}

\begin{abstract}
RESUMO
Este estudo analisa a rentabilidade das distribuidoras de combustíveis em relação à importação da gasolina A e do óleo diesel que representa um diferencial competitivo no mercado. Diante disso os objetivos de identificar e analisar a rentabilidade das distribuidoras de combustíveis em relação à importação da gasolina A e do Óleo diesel é de estrema relevância para os atores envolvidos. O estudo se justifica por discutir tal questão e apontar tendências de mercado que poderão beneficiar o setor de distribuição de combustíveis. O processo metodológico desta pesquisa se divide em uma revisão bibliográfica sistemática, no processo exploratório e análise de dados secundários quantitativos. Analisando o contexto apresentado, é possível inferir que a adoção da rentabilidade das distribuidoras de combustíveis em relação à importação da gasolina A e do óleo diesel é de suma importância para o fortalecendo da estratégia adotada pela organização afim de, garantir a sobrevivência no mercado de combustíveis.
\end{abstract}

Palavras-chave: Importação, distribuição de combustíveis, Gasolina A, Óleo Diesel

\section{PROFITABILITY OF FUEL DISTRIBUTORS REGARDING THE IMPORTS OF GASOLINE AND DIESEL OIL}

\begin{abstract}
This study analyzes the profitability of fuel distributors in relation to the importation of gasoline $A$ and diesel oil, which represents a competitive differential in the market. Therefore, the objectives of identifying and analyzing the profitability of fuel distributors in relation to the importation of gasoline $A$ and diesel oil is of great relevance to the actors involved. The study is justified by discussing such issue and pointing out market trends that could benefit the fuel distribution sector. The methodological process of this research is divided in a systematic bibliographical revision, in the exploratory process and analysis of quantitative secondary data. Analyzing the presented context, it is possible to infer that the adoption of the profitability of the fuel distributors in relation to the importation of gasoline $A$ and the diesel oil is of paramount importance to the strengthening of the strategy adopted by the organization in order to guarantee survival in the fuel market .
\end{abstract}

Keywords: Import, fuel distribution, Gasoline A, Diesel Oil 


\section{INTRODUÇÃO}

Desde os primórdios já se utilizava a energia, a matéria prima era a madeira como fonte de calor, no decorrer dos anos após a intensificação do crescimento populacional a busca por fontes de energia aumentou consideravelmente. Na segunda Revolução Industrial na metade do século XIX por volta de 1850, contribuiu para a propagação do combustível, apesar da concorrência da época ser com o carvão mineral.

As fontes de energia podem ser classificadas: renováveis e não renováveis. As renováveis são os que não têm limite estabelecido, sendo duradouras como biomassa, hidráulica, eólica e geotérmica, porém as energias não renováveis se esgotam e não serão repostas, pois seus recursos são limitados e escassos levam milhões de anos para sua formação como o petróleo, gás natural, carvão mineral e o urânio, que atualmente são estas as fontes de energia mais utilizadas que temos em cenário mundial representam mais de $85 \%$ de energia gerada (MOREIRA, 2017).

Considerando o mercado de derivados de petróleo cada vez mais competitivo, as empresas estão buscando se adequar na área econômica que traz sucessivas inovações e exige que as organizações estejam preparadas para as mudanças constantes causadas pela comercialização dos combustíveis.

Desenvolve-se em paralelo da comercialização internacional "a exportação compreende a saída temporária ou definitiva em território nacional de bens ou serviços originários ou procedentes do país, a título oneroso ou gratuito" (RECEITA FEDERAL, 2014), o índice da escala produção aumenta, a produtividade e demanda os benefícios pertinentes a diminuição da carga tributária em compensação do recolhimento dos impostos internos na exportação no crescimento de seus processos de qualidade para estar de acordo com a especificação vigente.

A importação é o ingresso seguido de internalização de mercadoria estrangeira no território aduaneiro. Em termos legais, a mercadoria só é considerada importada após sua internalização no país, por meio da etapa de desembaraço aduaneiro e do recolhimento dos tributos exigidos em lei. $O$ processo de importação pode ser dividido em três fases: administrativa, fiscal e cambial (SISCOMEX, 2017).

Ao país comprador a característica da importação se dá por meio do custo baixo e uma boa volatilidade cambial com sua variação podendo estar menor ou apropriada ao mercado, podemos concluir que a importação é uma parte do incentivo governamental para melhorar o mercado doméstico.

A maior liberdade do setor coloca uma nova questão na mesa, qual é a rentabilidade da importação de combustíveis, concomitantemente é sabido que quaisquer mudanças nas políticas fiscais podem impactar fortemente os atores envolvidos, para o setor as maiores influências são por meio dos impostos: PIS (Programas de Integração Social), COFINS (Contribuição para Financiamento da Seguridade Social) e PMPF (Preço médio ponderado ao consumidor final).

No país a comercialização de gasolina são: gasolina $A$, sem etanol e a gasolina $C$, nos especificaremos na gasolina A, segunda a descrição da ANP Resolução no 684/2017 "os hidrocarbonetos presentes na gasolina pertencem, principalmente, às classes das parafinas (normal ou ramificadas), olefinas, naftênicos e aromáticos, formados por cadeias de 4 a 12 átomos de carbono, com pontos de ebulição variando de 30 으 a 215 으, vendida pelos importadores e produtores". Na Resolução ANP no 686/2017 "O óleo diesel é um combustível líquido derivado de petróleo, composto por hidrocarbonetos com cadeias de 8 a 16 carbonos e, em menor proporção, nitrogênio, enxofre e oxigênio".

Sendo assim, identificar e analisar a rentabilidade das distribuidoras de combustíveis em relação à importação da gasolina $A$ e do Óleo diesel é de estrema relevância para os atores envolvidos. Da mesma forma que, identificar e desenhar as vantagens trazidas pela nova política nacional dos combustíveis importados. 
Discutir tal questão e apontar tendências de mercado poderá beneficiar o setor de distribuição de combustíveis, por meio das informações disponibilizadas, é possível obter maior entendimento do mercado atual e amenizar os impactos causados pela instabilidade da nova política de preços da estatal.

\section{METODOLOGIA}

O processo metodológico desta pesquisa se divide em uma revisão bibliográfica sistemática, no processo exploratório e analise de dados secundários quantitativos. A revisão bibliográfica sistemática caracteriza-se por evidenciar os métodos da busca e as escolhas feitas pelos pesquisadores.

A pesquisa bibliográfica é elaborada com base em material já publicado. Tradicionalmente, esta modalidade de pesquisa inclui material impresso, como livros, revistas, jornais, teses, dissertações e anais eventos científicos. Todavia em virtude da disseminação de novos formatos de informação, estas pesquisas passaram a incluir outros tipos de fontes, como discos, fitas magnéticas, CDs, bem como material disponibilizado pela internet (GIL 2010, p. 29).

A busca desta pesquisa foi feita pela Scielo, portal de revistas brasileiras que abrange uma coleção de periódicos científicos brasileiros, e Google Acadêmico.

Nesta busca de artigos, o objetivo era identificar aqueles que tinham a seguinte característica: após o aumento da produção norte américa e a queda dos preços em 2014 no cenário internacional deu origem a elevação dos preços no mercado domestico, pois a pratica da fixação dos preços antigamente era abaixo da paridade internacional fazendo com que ocorresse a diminuição da participação da estatal junto ao mesmo (ALMEIDA, 2015). O processo exploratório tem como principio a identificação e compreensão de um novo fato relevante que para as distribuidoras de combustíveis sobreviver no mercado identificamos alguns fatores como cotações internacionais, taxa de cambio, custo de internação e fretes marítimos que a partir de 2015 derem inicio a importação de combustíveis de forma independentes trazendo maior concorrência nos preços (BURNQUIST, 2016). Para acompanhar atualidade do mercado precisamos entender:

O regime aduaneiro especial de importação de petróleo bruto e seus derivados (Repex) é o que permite a importação desses produtos, com suspensão do pagamento de impostos federais, da contribuição para o PIS/ Pasep IMPORTAÇÃO e da COFINS IMPORTAÇÃO, para posterior exportação, no mesmo estado em que foram importados (art. 463 do RA). Esse regime é utilizado por empresas petrolíferas, habilitadas pela Secretaria da Receita Federal e autorizadas pela Agência Nacional de Petróleo a exercer as atividades de importação e exportação de petróleo e seus derivados. (SOUZA, 2010 p.39).

A relevância desta pesquisa por meio de uma abordagem exploratória segundo Gil (2007). "Este tipo de pesquisa tem como objetivo proporcionar maior familiaridade com o problema, com vistas a torná-lo mais explícito ou a construir hipóteses".

Por fim para alcançar o objetivo o método utilizado neste artigo para atender os objetivos de forma coerente optou-se por uma abordagem quantitativa onde busca-se a análise dos dados para uma compreensão do assunto. De acordo com Fonseca (2002, p. 20). "A pesquisa quantitativa recorre à linguagem matemática para descrever as causas de um fenômeno, as relações entre variáveis, etc.". 


\section{EMBASAMENTO TEÓRICO}

O primeiro poço comercial de petróleo proporcionou em larga escala de produção no dia 29 de setembro em 1859 e a partir de então comemorasse o dia mundial do petróleo, localizado em Titusville, Pennsylvânia (Espinola, 2013). Desde então a demanda do petróleo e seus derivados tem crescido mundialmente como fonte de poder. Já no Brasil segundo Morais (2013, p.22):

Nesta fase foi criada a PETROBRAS, em 1953, com a missão de resolver o problema da alta dependência brasileira do petróleo importado. Ao empreender a tarefa, a empresa descobriu, nos seus primeiros anos de atividades, importantes campos de petróleo em vários estados do Nordeste, mas, em meados da década de 1960 constatou que as descobertas em terra não estavam ocorrendo em volumes capazes de diminuir a dependência do petróleo importado.

Décadas se passam e por fim no ano de 2006, a necessidade nacional passou a ser suprida com a própria produção do petróleo nacional, após longa dependência dos produtos importados, porém o mercado em constante expansão tornou novamente a precisar dos produtos importados.

O governo anunciou em junho de 2017, uma nova política de preços no setor, a principal empresa do setor a estatal Petróleo Brasileiro S.A. (doravante Petrobras), vinha sofrendo forte concorrência dos combustíveis importados e a nova política de preços em busca de torná-la mais competitiva no mercado doméstico.

O Grupo Executivo de Mercado e Preços (GEMP) é o responsável pelo reajustes dos valores dos combustíveis nas refinarias Petrobras seus componentes são pelo Presidente da companhia, diretor executivo financeiro e de relacionamento com investidores e pelo diretor executivo de refino e gás natural, no mínimo se reúnem pelo menos uma vez ao mês. (PETROBRAS, 2017)

Segundo dados da ANP (Agência Nacional do Petróleo, Gás Natural e Biocombustíveis) podemos identificar o desempenho do setor de derivados de petróleo em ralação a exportação (receita) e importação (dispêndio) no ano de 2015 e 2016 na tabela a seguir.

Tabela 1. Valores da importação e da exportação de derivados de petróleo 2015 e 2016

\begin{tabular}{|c|c|c|c|}
\hline \multirow{2}{*}{ Derivados de petróleo } & \multicolumn{2}{|c|}{ Importação e exportação (mil US\$ FOB) } & \multirow{2}{*}{$\begin{array}{c}16 / 15 \\
\%\end{array}$} \\
\hline & 2015 & 2016 & \\
\hline \multicolumn{4}{|l|}{ Total } \\
\hline Dispêndio (importação) & 4.462 .817 & 3.811 .895 & $-14,59$ \\
\hline Receita (exportação) & 409.020 & 468.690 & 14,59 \\
\hline \multicolumn{4}{|l|}{ Gasolina A } \\
\hline Dispêndio & 1.047 .669 & 915.079 & $-12,66$ \\
\hline Receita & 247.541 & 232.504 & $-6,07$ \\
\hline \multicolumn{4}{|l|}{ Óleo diesel } \\
\hline Dispêndio & 3.415 .147 & 2.896 .816 & $-15,18$ \\
\hline Receita $^{3.4}$ & 161.480 & 236.186 & 46,26 \\
\hline
\end{tabular}

Como demonstra a tabela acima à importação em comparação a exportação houve uma diminuição, isto ocorreu pela nova política de preço adotada pela estatal no mercado interno para competir no externo e estar dentro das negociações afim de aumentar sua participação no mercado nacional e internacional que estava perdendo sua atuação.

A necessidade de importação se manteve para suprir a demandando apesar das vendas internas que tiveram queda. No ano de 2014 houve benefícios econômicos por meio da importação com isso, ANP registrou um acréscimo de $12 \%$ das importadoras autorizadas, sendo 
um forte estimulo para aquecer o mercado interno, pois seus preços elevados diferente dos preços do cenário internacional que favorecia a importação por seus preços em queda. Segundo o Sindicato Nacional das Empresas Distribuidoras de Combustíveis e de Lubrificantes (SINDICOM) diz que "Os estados com maior quantidade de registros para importação continuam sendo Espírito Santo, com 35 empresas, São Paulo, com 31 empresas, e Rio de Janeiro, com 30”.

Gráfico 1. Percentual de importação

IMPORTAÇÃO DIESEL A

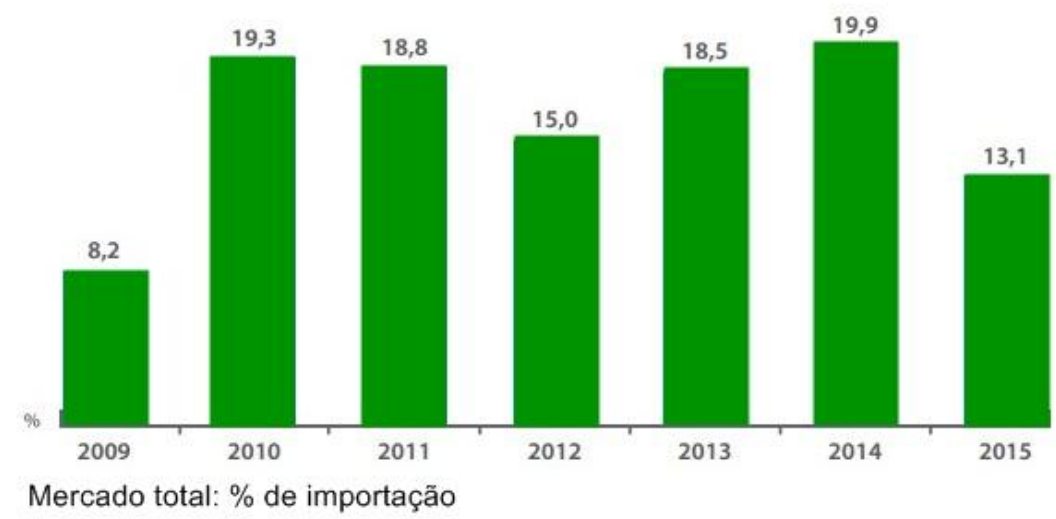

Fonte: ANP, adaptada pelo autor

Em comparação ao ano de 2015 para 2013 e 2014 ocorreu de 38,4\% para 13,1\% no ano sofrido de 2015. Isto ocorreu pois no ano de 2014 apenas a Petrobras importava este produto consequentemente aproveitando o cenário de benefícios, pois os preços internos elevados e o internacional em queda, aumentando assim sua receita. No ano de 2015 as distribuidoras tiveram a iniciativa de buscarem importadores afim de, suprir a demanda do mercado tornando-se importadores independentes aquecendo o mercado com maior concorrência.

Gráfico 2. Percentual de importação

\section{IMPORTAÇÃO GASOLINA A}

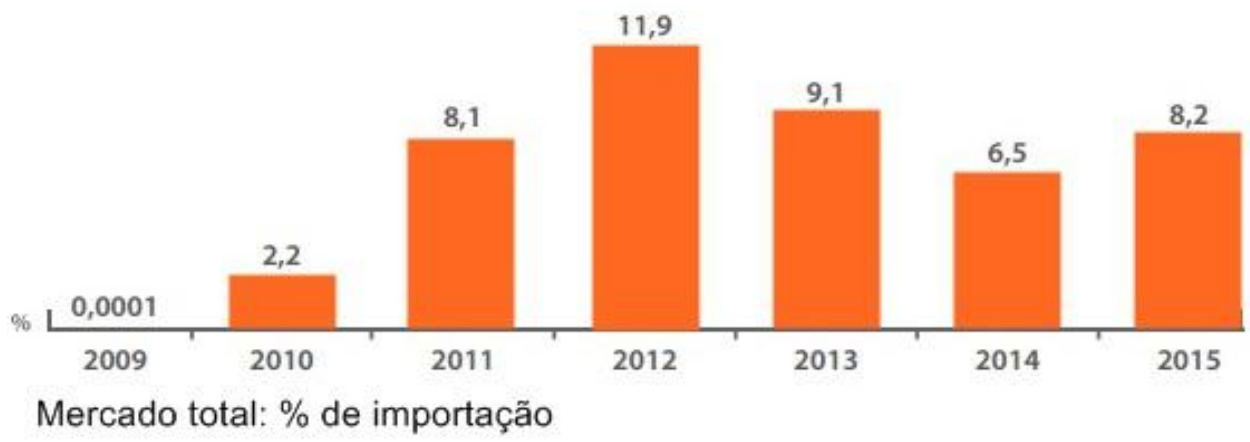

Fonte: ANP, adaptada pelo autor. 


\section{CONCLUSÃO E DISCUSSÃO}

A abertura do mercado não foi completa, as decisões beneficiaram algumas empresas que já tinham uma certa estrutura comercial, apesar dos aumentos eles foram pequenos e seletivos, para trabalhos futuros, faz necessário entender se no passar do tempo o mercado diminuirá sua concentração, caso contrário pode-se concluir que a abertura não trouxe benefícios ao mercado de combustíveis no Brasil.

Contudo, a participação da Gasolina A no ano de 2015 foi de 8,2\% no mercado total do País. Em comparação ao ano anterior ocorreu um aumento de $1,7 \%$ na participação do produto importado, trazendo vantagens econômicas pelo fato dos preços internos estarem altos e os internacionais em queda. De acordo com Sindicom (2016) "Isso trouxe atratividade extra as importações de gasolina A que se concentraram no 1ㅇ Trimestre de 2015".

\section{REFERÊNCIAS}

ALMEIDA, Edmar Luis Fagundes de; OLIVEIRA, Patricia Vargas de; LOSEKANN, Luciano. Impactos da contenção dos preços de combustíveis

no Brasil e opções de mecanismos de precificação. Revista de Economia Política, vol. 35, no 3 (140), pp. 531-556 jul-set. 2015.

BURNQUIST, Heloisa Lee; COSTA, Cinthia Cabral da. Impactos do controle do preço da gasolina sobre o etanol biocombustível no Brasil. Estud. Econ., São Paulo, vol.46, n.4, p. 1003-1028, outdez. 2016.

ESPINOLA. Aida. Ouro negro - petróleo no Brasil: pesquisa em terra, na plataforma continental e em aguas profundas. 1 Ed, Rio de Janeiro: Interciência, 2013. ISBN 978-85-7193-306-4.

FONSECA, João José Saraiva da. Metodologia da Pesquisa Científica. Fortaleza.

GIL, Antônio Carlos. Como elaborar projetos de pesquisa. 5. Ed. São Paulo: Atlas, 2010.

MORAIS, José Mauro de. Petróleo em águas profundas : uma história tecnológica da Petrobras na exploração e produção offshore. Brasília : Ipea : Petrobras, 2013. 424 p. : il., ISBN: 978-857811-159-5.

MOREIRA, José Roberto Simões. Energias renováveis, geração distribuída e eficiência energética / Alberto Hernandez Neto ... [et al.]; organização José Roberto Simões Moreira. - 1. Ed, Rio de Janeiro: LTC, 2017. II. ISBN: 978-85-216-3377-8.

SISCOMEX. Glossário. $2017 . \quad$ Disponível em: <http://portal.siscomex.gov.br/glossario/glossario_view?letra=l>. Acesso em: 24 nov. 2017

SINDICOM, Sindicato Nacional das Empresas Distribuidoras de Combustivéis e de Lubrificantes. 2016. Disponível em: .<http://www.sindopolis.com.br/wpcontent/uploads/2016/07/ANUARIO_2016_TOTAL_FINAL2_WEB-1.pdf>. Acesso em: 25 nov. 2017 
SOUZA, José Manuel Meireles de. Gestão do comércio exterior: exportação/importação.1. Ed. São Paulo: Saraiva, 2010. ISBN 978-85-02-11745-7. 